Article

\title{
Culturally Responsive Teaching: Its Application in Higher Education Environments
}

\author{
Laveria Hutchison ${ }^{1, *}$ and Leah McAlister-Shields ${ }^{2}$ \\ 1 Department of Curriculum and Instruction, University of Houston, Houston, TX 77204, USA \\ 2 Department of Mathematics, University of Houston, Houston, TX 77204, USA; lmcalister@uh.edu \\ * Correspondence: lhutchison@central.uh.edu
}

Received: 18 March 2020; Accepted: 20 April 2020; Published: 27 April 2020

\begin{abstract}
The application of culturally responsive teaching (CRT) in this article is used to provide a background into the instructional concept of CRT in higher educational settings and to provide examples for classroom pedagogical practice. This article provides instructional approaches that can be used in higher education classes to promote a cultural context to engage preservice teaching candidates who are seeking initial certification to become teachers-of-record and graduate-level teachers who are certified to understand and embrace the intersection of race, gender, religion, and regional cultures that contribute to identity. This article outlines instructional activities that can be used by faculty in higher education programs to assist their students with learning to co-construct culturally responsive lessons. This type of instruction should lead to a process in which faculty in higher educational settings can assist their preservice teacher candidates and graduate-level students in understanding the community in which they will serve or currently serve and to bring the funds of knowledge of their students into positive and productive learning environments.
\end{abstract}

Keywords: higher education; culturally responsive teaching; diversity; educator preparation programs

\section{Introduction}

The ability to receive an equal educational journey in the United States of America has consistently been a challenge for both racial and ethnic minorities. Since the historical period of slavery in this country, educational opportunities for minorities have both increased and declined. As mentioned by [1], since the 1960s, this country has experienced adequate progress regarding educational opportunities for minority students. However, the progress in attainment of educational opportunities has been minimum, and attrition rates are still unmatched among white students and non-white students $[2,3]$. It is also important to mention that while racially marginalized students are no longer legally separated in public education systems from white students, marginalized students continue to be separated from white and Asian students in academic achievement levels. Outcomes from research have indicated that learning disparities in the academic achievement of racialized minority students often surface by the fourth grade [4]. An example of this gap is found in reading achievement levels where white and Asian students score higher than racial and ethnic minority students [4].

According to the Texas Higher Education Coordinating Board [5], racial and ethnic diversity of students enrolled in institutions of higher education across the United States has grown significantly. The inclusion of student diversity in higher education settings is a result of the 1954 Brown v. Board of Education ruling [6]. The ruling enforced enrollment changes at traditionally white colleges and universities in the United States to provide opportunities for black and brown students, especially in southern states [7]. Data show that the combined rate of enrollment of African American and Hispanic student has increased from $13.2 \%$ to $31.6 \%$ over the last four decades (Figure 1). However, regrettably, the increase in the rate of enrollment for minority students outpaces their degree attainment. 


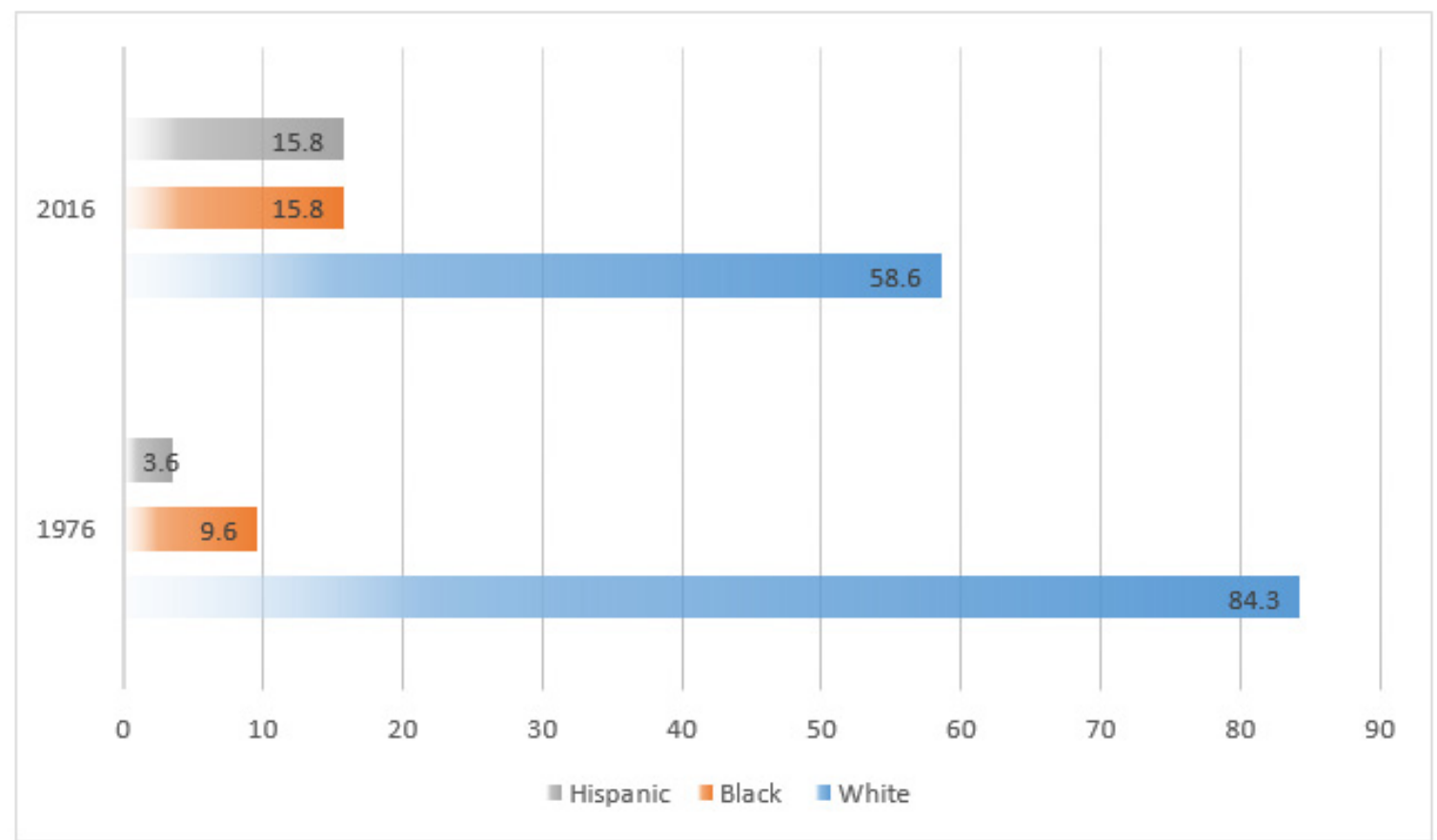

Figure 1. Percentages of students enrolled in U.S. colleges and universities in fall 1976 and fall 2016 as a function of race/ethnicity. Adapted from the National Center for Education Statistics. (2015). Projection of Education Statistics to 2024: Forty-third Edition. Retrieved from https://nces.ed.gov/ pubs2016/2016013.pdf.

Considering national and state trends when compared to white students, African American and Hispanic students often do not complete their undergraduate degree requirements [8]. For instance, of the 83,837 degrees and certificates awarded in 2012 at Texas community colleges, $41 \%$ were awarded to white students, 35.8\% to Hispanic students, and 11.8\% to African American students [5]. The difference in degree completion rates between minority students and white students broadens as achieved degree levels are awarded for associate's, bachelor's, master's, and doctorate degrees [7]. Higher education graduation rate trends are of a significant concern because of their correlation with increased socioeconomic mobility trends in the United States [9-12]. It is essential to acknowledge that non-white students do not complete graduation requirements as often and at a similar rate as their white peers. This result further contributes to peer groups falling below the poverty and educational levels in the United States [13].

Consequently, the concept of culturally responsive teaching (CRT) is used to present the discussion in this article. Gay [14] defines this teaching concept as "using the cultural knowledge, prior experiences, frames of reference, and performance styles of ethnically diverse students to make learning encounters more salient to them. It teaches to and through the strengths of these students" [14] (p. 31). Specific features of CRT can be traced back as early as the 1970s, in Forbes' [15] suggestion of the need for the development of an instructional strategy that is based on the local cultures of Native American students. Since the introduction of this instructional concept, more researchers $[14,16,17]$ have entered this theoretically-based dialogue.

\section{The Landscape of Higher Education in the United States}

The higher education arena has presented a dialogic discussion regarding segregation issues for several decades. In the 20th century, Georgia, South Carolina, and North Carolina were examples of states that intentionally formed racially separated higher education institutions for African American and white students who desired to obtain higher education degrees. Several racial groups have contributed to the dialogue of higher education. However, this dialogue regarding higher education 
attainment has been mainly focused on African American and white students. Because of this disparity, the United States government recognized that such powerlessness for college-aged students, in not having a choice or a voice in where they attend college, could produce significant negative implications. It has been noted that these negative implications could result in educational and socioeconomic disparities along with other negative factors. Consequently, several Supreme Court cases (Sipuel v. Board of Regents of the University of Oklahoma in 1948, McLaurin v. Oklahoma State Regents in 1950, and Sweat v. Painter in 1950) have assisted in the enforcement of the decision that separate higher education provided to African American students does not provide an equal education.

A 2003 Supreme Court ruling indicated that diversity in classroom settings enables students to learn to "become effective citizens and substantial leaders in a diverse society" [18] (p. 10). Representative of this ruling, an increase in the enrollment of racialized minority students in institutions of higher education occurred, spurring a consideration for the use and the implementation of culturally responsive teaching in higher education classrooms. Subsequently, culturally responsive teaching has emerged as an essential aspect in teacher training, as this instructional approach provides educators with useful strategies that build inclusion and focus on the academic achievement of students using culture as a cognitive scaffold. Although often recognized as an important aspect of teacher development, students enrolled in educator preparation programs often complete their program of study without being introduced to societal issues produced by race, class, and culture. As an example, McIntosh [19] noted that many white people experience life without a need to defend or to explain themselves because they are not minorities [20].

As educator preparation programs prepare preservice teacher candidates to become certified and graduate programs prepare certified educators to connect with students in school settings, these educators should be prepared to understand that racial and cultural identities are humanistic factors that should be considered, taught, and demonstrated in their educational environments. Ladson-Billings [21] suggested that higher education environments should provide curricula that are culturally relevant to empower their students. The instruction provided by higher education faculty should include instructional and conceptual theories, educational resources, and strategies that close the cultural gap between instructors and their learners. The application of CRT should be viewed as needed and useful in the instruction of all students. Presenting evidence for both preservice teacher candidates and for graduate-level students shows that diverse classroom settings can provide a pathway for positive teaching and learning. Developing and structuring educational programs that include CRT will contribute to the preparation of preservice teacher candidates and to graduate-level students in learning to demonstrate concepts that will help their students become critical analyzers, capable of using written and oral literacy structures, scientifically engaged, and proficient in navigating all the aspects of their academic arena [22]. Teachers should always emphasize academic excellence so that their students can increase their overall academic achievement levels [23].

\section{Applying Culturally Responsive Teaching in Classrooms Settings}

The absence of inclusive social encounters in higher education institutions could be a factor in the reduction of the completion of degree requirements among marginalized student groups [24,25]. The access and capacity to participate in student organizations may contribute to the overall social experience, especially among undergraduate college students. The participation of professors in identifying pathways to assist with the improvement of increased graduation rates among their culturally diverse student populations is also of significance. In identifying the role of professors in reducing the current college completion gaps among minority student groups, professors need to recognize and to value student cultures in higher education settings. The recognition of using the cultural experiences of diverse student groups in classroom settings emerged from research reported by Banks [26] on multicultural education. Further, Nieto [27] (p. 305) added to the dialogue by providing information supporting the role of multicultural education as being "a process of comprehensive 
school reform and basic education for all students and accept[ing] and affirm[ing of] the pluralism that students, their communities, and teachers reflect."

Since Banks [26], other researchers [14,16,17,20,28-31] have identified the concept of culture as a significant and useful teaching tool in K-16 and beyond classroom settings. Expanding on the philosophy of Banks regarding multicultural education, Ladson-Billings [32] has contributed to the discussion of CRT. In her book, The Dreamkeepers: Successful Teachers of African American Children, Ladson-Billings discussed how the adoption of culturally inclusive instruction helped African American students in an elementary school gain high achievement levels. Teachers who expected high levels of excellence from their students on classroom assignments and assessments, productive behavior and attitude actions, cultural competence, and an awareness of power differences to resolve struggles in society found positive academic achievement results $[17,32]$. To continue this discussion, Ladson-Billings [17] identified CRT as a practice that enhanced the collective empowerment of students by promoting student success.

The dialogue regarding the implementation of CRT in instruction in higher-educational settings has been noted by researchers $[33,34]$ by recommending the value of considering one's culture when crafting curriculum and offering instructional concepts. As discussed by several authors, the use and the application of CRT in higher education are necessary, and CRT's implementation is overdue. This dialogue further connects to the omission of CRT practice regarding the instruction of marginalized students, showing that research and recognition of bias are more important than the delivery of instruction that captures CRT practices. Organizations such as the American Psychological Association [35] also acknowledge the need to address bias when conducting and analyzing research, in addition to the need to consider the personal bias of researchers when developing, discovering, and sharing new informational concepts.

Other considerations regarding the transfer of CRT concepts into higher education settings should include institutional considerations and changes, such as recruiting, hiring, and retaining more diverse faculty to serve all students, including minority students [36]. These institutional changes should form a transfer from disciplinary isolation to an inclusive and collaborative environment for developing and promoting research-based practices and program structures [37]. By doing so, faculty can competently navigate the convergence of race, culture, class, gender, and disability, by becoming inclusive educators who prepare both future teachers and in-service teachers who teach all students using an inclusive lens [33].

\subsection{Culturally Responsive Teaching in Higher Educational Settings}

The work of education faculty, including and delivering the instructional concepts of culturally responsive teaching, will support their teacher candidates and graduate-level candidates in learning to accept and to incorporate cultural competence as a part of their identity and into their instructional practice. To accomplish this, however, participants will need to evaluate their previously held beliefs, consider making personal belief changes, and dedicate themselves to teaching all students who make up various types of learning environments. Therefore, the inclusion of (a) faculty evaluating and developing course content that uses the constructs of CRT, (b) a commitment of current and future educators to reflect on their beliefs and biases through both written and oral contexts, and (c) CRT practices used in instruction by preservice teacher candidates and current educators in the development of instruction and assessments that consider student achievement will improve the classroom setting for minority students.

Recent research by Moran [38] supports the use of CRT practices when developing and identifying pedagogy course content at all levels in the educational arena. This research also recommends the adoption of self-reflection practices that include teacher-focused action-research classroom investigation results that are reviewed and discussed in a broad context with educators, administrators, parents, and community advocates. An example of this research process was designed by Young [39], 
where certified teachers and administrators documented their path of incorporating the components of CRT into engaged and student-centered activities.

As teacher education professors make assignments for their preservice teacher candidates and their graduate-level candidates to submit for evaluation, there should be an expected focus and inclusion of CRT strategies threaded within the construction of each assignment. Additionally, when reviewing self-reflections made by students in higher education classes at both the undergraduate and graduate levels, professors should seek evidence of collaboration between the candidates in the higher education programs and their students in classroom settings. Higher education faculty teaching in educator preparation programs and other graduate-level degree programs should consistently assess the work of their students in search of inclusive instruction that minimizes cultural biases [22]. As an expected outcome of the inclusion of CRT practices in school settings, there should be evidence in assignments that require high intellectual rigor. The central theme of CRT in EC-12 instruction and higher education settings suggests that educators "teach to and through" the cultural identities of students [14] (p. 34). Educators who implement this type of instruction demonstrate the characteristics listed in Table 1.

Table 1. Characteristics of culturally responsive teaching [14] (p. 29).

\begin{tabular}{cc}
\hline Number & Characteristics \\
\hline 1 & [Teachers] acknowledge the legitimacy of the cultural heritage of different ethnic groups as \\
legacies that affect students' dispositions.
\end{tabular}

There is adequate research that supports the use of CRT in EC-12 classroom environments [14,40]. It is important to note that there is limited research on the utilization of CRT practices in higher education instruction [41]. The theory of CRT, as identified by Ladson-Billings [17], is notably applicable in higher education settings preparing learners to function in uniquely diverse work environments where they are preparing their students to become global workers and leaders. Researchers of culturally responsive teaching suggest that individuals who have gained an understanding of cultural diversity may also witness the decline of the disenfranchisement among traditionally marginalized groups $[42,43]$.

According to Bustamante [44], scholars in academic settings do not always employ the use of culturally responsive teaching practices. Additionally, other than the implementation of CRT in the community college setting, there has been a limited discussion in the literature on the use of CRT practices among preservice teacher education candidates and graduate-level education candidates in institutions of higher education. As an example, Smith and Ayers [45] investigated the impact of CRT in an online learning environment involving Latinx students who were enrolled in community college. Smith and Ayers found that "technologically mediated learning experiences may accommodate the singularities of a dominant Western culture at the expense of cultural responsiveness to the backgrounds of all participants" [45] (p. 401). Latinx and African American students were also found to have cognitive styles for acquiring knowledge through field-dependent structures and not through field-independent structures. Collaboration translates to the understanding that Latinx and African American students learn more effectively in classroom settings that incorporate and encourage peer-to-peer social connections and collaborative dialogue exchanges. Therefore, there is a need to continue to develop equitable and culturally responsive online instructional opportunities that allow for collaboration among Latinx and African American students who attend community colleges. Smith and Ayers [45] suggested that professors should consider designing online instruction that 
would allow for the incorporation of both asynchronous and synchronous formats. At this time, there is limited information on the use of CRT in online environments in four-year college settings [41]. There is also an increase in the number of four-year colleges and universities that include diversity statements that embrace the inclusion of all people on their campuses. This tends to promote institutional advancement. However, there is a need for administrative action and change in policy procedures that would promote the recruiting, hiring, and retaining of faculty from diverse and marginalized groups who will become tenured faculty members $[14,46]$.

\subsection{Culturally Responsive Teaching in the Online Delivery of Courses in Higher Education}

The inclusion of online degree programs in higher education has seen significant and continued growth over the period from 2005 to 2015 . During this period, the number of students enrolled in online courses increased from 3.5 to 5.8 million $[47,48]$. Because of this expansion of online programs and course offerings, there is a need to recognize that diverse students also use online learning spaces; therefore, there is a need for instructors delivering online courses to become considerate of the various learning styles their students bring into the online environments [49]. The cultural differences that may occur between professors and their students in the online environments can often cause the integration of CRT practices to be a challenge when providing instruction offered through online learning environments [49]. According to Heitner and Jennings [49], the challenges that are associated with online instruction that does not consider cultural diversity may affect the caliber of online teaching and learning.

It is necessary to emphasize that the cultural capital acknowledgment of both the students and of their higher education professors can assist with the improvement of learning [50]. Recommendations for the application of CRT in the online instructional environments can include professional development sessions, an application of the concepts learned in these professional development sessions, ongoing developmental training that highlights new delivery trends, and mentoring with follow-up discussions for faculty to highlight their use of CRT. Enhancing the capacity for instructors to move from the understanding of different CRT practices to the implementation of these practices to an online format will assist in building congenial communities for students who engage in online instruction [49].

\subsection{Factors That Influence the Use of Culturally Responsive Teaching in Higher Educational Settings}

Some factors have been associated with both the encouragement and the hindrance of the inclusion of CRT in higher education environments. PeQueen [51] noted that although the diversity of college students continues to increase, higher educational systems have been slow in the recruiting, hiring, and retaining of a diverse faculty workforce. Therefore, with the increased number of postsecondary students from diverse backgrounds along with the intersection of student demographics, the one-size-fits-all method of teaching no longer meets the instructional demands of diverse classrooms in the United States [16,51].

For faculty who teach in higher education institutions, it may take several rounds of presentations of CRT practices before its implementation in higher educational settings can be found in the delivery of instruction. Furthermore, rethinking the way that faculty are evaluated by both their students and their peers to include more of an emphasis on CRT approaches should promote the significance of incorporating these instructional practices in higher education $[51,52]$. Course evaluations should be restructured to include CRT items to gather feedback from students regarding the effective delivery of CRT instructional practices. Rethinking the course evaluation process used to determine the instructional effectiveness of CRT can highlight how administrators value the growing number of diverse students in higher educational settings. To this point, college and university leadership should offer faculty enhanced support for the construction of course materials that include components of CRT methods [51].

The differentiated academic readiness levels of students entering and remaining in higher education settings can serve as a factor that could challenge the implementation of the use of 
CRT [51]. Selective mental beliefs can also alter the application of CRT. As an example, a place of deficit-minded thinking that assumes that minority students are incapable of having the academic capacity to perform in college-level classes can influence the inclusion of CRT in higher educational settings [53]. Higher education administrators and educators should be careful to not overlook the need for pedagogical training and the use of instructional shifts that show the application of ideas learned during these trainings. Finally, higher education leaders should assign merit based on the use of CRT in instruction [53].

\subsection{Everyday Examples of Culturally Responsive Teaching in Higher Education}

Higher education faculty should be committed to engaging their students in all aspects of learning. As educators, we can assist our teaching candidates by using strategies that will build their capacity to value the communities and the cultures of their students, to expand their personal cultural views, and to build community with the students and families they serve. There are strategies that the authors of this article have found useful in implementing aspects of CRT in higher educational settings. Table 2 provides several practices that could be used to incorporate and to promote CRT. Examples by way of instructional scenarios are included in the next section of this article to highlight how higher education faculty can use CRT practices in their instruction.

Table 2. Culturally responsive teaching (CRT) in educator preparation programs.

\begin{tabular}{|c|c|c|}
\hline CRT Strategy/Resource & Definition & Classroom Practice \\
\hline $\begin{array}{c}\text { School-Wide Cultural Competence } \\
\text { Observation Checklist (Nelson, } \\
\text { Bustamante, } \\
\text { and Onwuegbuzie, 2009) }\end{array}$ & $\begin{array}{l}\text { This is a 33-item assessment that is } \\
\text { designed to determine the degree } \\
\text { of diversity found on a campus. }\end{array}$ & $\begin{array}{l}\text { Students used the assessment to } \\
\text { rate diversity and cultural aspects } \\
\text { found on their campus. }\end{array}$ \\
\hline $\begin{array}{l}\text { Equity Audit (Skrla, Mckenzie, } \\
\text { and Scheurich, 2008) }\end{array}$ & $\begin{array}{l}\text { This is an assessment that contains } \\
12 \text { indicators for assessing equity } \\
\text { and inequity in the areas of teacher } \\
\text { quality, student programs, } \\
\text { and student achievement. }\end{array}$ & $\begin{array}{l}\text { Students used the assessment to } \\
\text { conduct equity audits to evaluate } \\
\text { a variety of components related to } \\
\text { school programs, student state } \\
\text { examination scores, and other } \\
\text { aspects such as graduation rates. }\end{array}$ \\
\hline $\begin{array}{l}\text { Exploring Your Culture } \\
\text { (Fralick, 2015) }\end{array}$ & $\begin{array}{l}\text { This is an assessment that uses } \\
\text { seven items for a student to } \\
\text { evaluate their personal cultural } \\
\text { beliefs and experiences. }\end{array}$ & $\begin{array}{l}\text { The assessment allows } \\
\text { participants to think about their } \\
\text { own lived experiences. This can be } \\
\text { followed by group discussion on } \\
\text { diversity and culture. }\end{array}$ \\
\hline $\begin{array}{l}\text { Community Visit to Build Cultural } \\
\text { Knowledge (Hutchison et al., 2018) }\end{array}$ & $\begin{array}{l}\text { This is an organized and pre-set } \\
\text { visit to a community that is led by } \\
\text { community leaders to help } \\
\text { teachers learn more about the } \\
\text { social context of their } \\
\text { campus community. }\end{array}$ & $\begin{array}{l}\text { Pre-service and in-service teachers } \\
\text { can tour their campus community } \\
\text { over two days. The tour should be } \\
\text { led by a community leader who } \\
\text { can provide and explain historical } \\
\text { information, financial information, } \\
\text { and community resources. } \\
\text { The leader can arrange for brief } \\
\text { meetings community dwellers and } \\
\text { can have a meal in a home or a } \\
\text { community restaurant. }\end{array}$ \\
\hline
\end{tabular}

\section{Higher Education Scenarios and Guiding Statements with Questions}

The focus of this article is on the preparation of faculty in higher education settings to become inclusive via the implementation of CRT in courses that are offered at both the undergraduate level and the graduate level of instruction. The intent of higher education faculty demonstrating the inclusion of CRT practices in their instruction is to assist their student teachers and practicing teachers in learning ways to incorporate CRT into their instruction in K-12 grade classroom instruction. We have developed 
four guiding statements and questions along with three scenarios that faculty in higher education can consider applying in the rethinking of their instructional practice for their students. We recommend using the following questions and statements to guide the discussion related to each scenario.

\subsection{Guiding Statements and Questions to Use with the Scenarios}

1. Identify the culturally sensitive issues and biased beliefs embedded in each scenario.

2. How can you use the components of CRT to reconstruct each scenario?

3. Identify practices that could be used in each scenario to promote the inclusion of CRT within a post-secondary context.

4. What did each scenario teach you about cultural bias?

\subsection{Scenario I: Seminar on Professional Leadership (Dr. Timber Is a Made-up Instructor)}

Dr. Timber's seminar titled Professional Leadership offers education students the opportunity to participate in meaningful dialogues about the school climate and instructional practices used to address issues regarding discipline on racially and economically diverse school campuses. During the first seminar session, Dr. Timber encouraged students to share some of the issues they were facing as leaders and as teachers on campuses. As the class progressed, a discussion formed around the questioning of the use and the effectiveness of restorative justice as a disciplinary approach in school settings. One student aggressively stated that students are out of control in the school setting associated with his/her current position, that this type of discipline requires time to implement, and that this approach often does not work with the students on his/her campus. When asked to describe his/her school demographics, the response was that the school enrollment was composed of African American and other non-white students. Dr. Timber thoughtfully asked questions about the school's culture and climate related to this campus. Dr. Timber also included comments about the importance of school leadership and faculty connecting to the community surrounding the school by participating in social activities and other activities that include shopping in community venues and eating in local restaurants.

Additionally, Dr. Timber discussed the importance of involving parents in the disciplinary decisions that pertain to their children. Dr. Timber recommended that the class engage in additional discussions regarding this issue following investigations of the professional literature. Dr. Timber recommended that the students reflect on CRT recommendations for disciplinary practices that they may consider using on their campuses.

\subsection{Scenario II: Benza's Dilemma}

The next scenario occurred when one of Dr. Timber's graduate students, Benza, engaged in a discussion about how some of the eighth-grade teachers on her instructional team can connect with their students. She highlighted one of her peers in significant detail regarding the connection this teacher has with most of the students. Benza described the student population of her middle school campus as being economically disadvantaged and culturally diverse with most of the students being either African American or English learners. During the discussion, Benza made such comments as, "My students are not interested in the subject I teach", and "I have noticed my students connecting better and talking more with my co-teaching partner than with me." As she shared her experience, Benza explained that, as a white female, who has worked at the school for five years, she has never seen the need to connect with the community surrounding the campus. She also mentioned that her co-teaching partner-who is an African American female, grew up in the same neighborhood as the school, attended schools in the area, has now returned as a middle school science teacher, and is also a resident in the community-may have an advantage of understanding the complexities of the school's environment. Benza indicated that she believes that the students connect to her co-teaching partner because of their similar cultural backgrounds. Benza went on to share that she grew up in a 
middle-class neighborhood and attended schools with access to very different resources. She explained that she appreciates her colleague for returning to her former community to work and to live. However, Benza indicated that her goal is to rescue these kids from their environment and to help them achieve an education that will allow the students to live a better life and in a better community. Benza also shared that she currently lives in a community that is very similar to where she grew up during her school years before entering college. Benza continued her rant and added that her co-teaching partner was able to build a positive rapport with her students and design a class environment of engagement and productive learning. Frustrated, she expressed that she needed help with her current teaching situation and asked for advice from her peers and professor about how she could improve her current teaching situation.

\subsection{Scenario III: Experiencing a Biased Situation}

Ross is an African American male student who wants to become a teacher. While waiting for his advisement session with his faculty advisor, Dr. Smith, Ross overheard a conversation between his advisor and a white student from the same program discussing a research project that was seeking research assistants who were education students. Dr. Smith indicated to the white student that he thought the white student should apply for a position as a research assistant for this project. The white student was heard thanking Dr. Smith and indicating that he would apply for the position. Ross was excited about what he overheard and asked Dr. Smith about this research opportunity. Dr. Smith told Ross that, although he had obtained a 4.0 grade point average at his previous college before entering this university, this research opportunity would probably be too tricky for Ross and that he would probably not be considered as an applicant. Dr. Smith also stated that students who enter this university from a community college do not always pass the state assessment for initial teacher certification and that he thought that Ross should study more and not work. Ross was emotionally concerned after his conversation with Dr. Smith and left the meeting forming doubts about his educational and professional path going forward.

\section{Conclusions}

We believe that the inclusion of culturally responsive teaching strategies should be considered as a foundational construct in higher education settings. It is also our belief that the inclusion of this practice is impacted by the degree to which faculty are prepared to offer relevant and inclusive educational experiences that build trust, increase student capacity, and leverage students' funds of knowledge as a cognitive scaffold for student success [54]. As suggested by Gay [14] (p. 44), schools should "encourage dialogue and critical thinking between the teacher and the students." In consideration of CRT practices, it is vital to assist higher education students in understanding the need to consider and apply aspects of the communities that represent the environments of their students. It is vital for researchers and practitioners in higher education settings to (re)frame their development of curriculum and pedagogical approaches [50]. This (re)framing is important because it provides an opportunity to reflect and robustly probe how instruction happens in higher education settings and whether we are meeting students where they are. This is a central characteristic of effective teaching-meeting students where they are and elevating their capacity to learn [54,55]. Such a process of examination, modification, and reflection of instruction to employ CRT will not only allow education students in higher education settings to see examples of CRT in practice but will additionally allow teaching students themselves to make cognitive connections to content that facilitates learning.

Author Contributions: Both authors contributed to the development of the literature review and educational scenarios. All authors have read and agree to the published version of the manuscript.

Funding: This research received no external funding.

Acknowledgments: To our students who challenge us every day to value their lived experiences.

Conflicts of Interest: The authors declare no conflict of interest. 


\section{References}

1. Lloyd, K.M.; Tienda, M.; Zajacova, A. Trends in educational achievement of minority students since Brown v. Board of Education. In Achieving High Educational Standards for All: Conference Summary; Ready, T., Edley, C., Snow, C., Eds.; National Academies Press: Washington, DC, USA, 2001; pp. 1-25.

2. Current Population Survey. College Enrollment and Work Activity of 2012 High School Graduates; Issue USDL-130670; US Department of Labor-Bureau of Labor Statistics: Washington, DC, USA, 2013.

3. National Center for Education Statistics. Digest of Education Statistics: 2011 (NCES 2011-001). 2012. Available online: https://nces.ed.gov/pubsearch/pubsinfo.asp?pubid=2012001 (accessed on 23 April 2020).

4. National Center for Education Statistics. NAEP Data Explorer. 2013. Available online: http://nces.ed.gov/ nationsreportcard/naepdata/dataset.aspx (accessed on 19 February 2014).

5. Texas Higher Education Coordinating Board. Interactive Access to Data. 2013. Available online: http: //www.txhighereddata.org/Interactive/Accountability/ (accessed on 23 April 2020).

6. Malone, B.F. Before Brown: Cultural and social capital in a rural Black school community, WEB Dubois High School, Wake Forest, North Carolina. N. C. Rev. 2008, 85, 416-447.

7. National Center for Education Statistics. Projection of Education Statistics to 2024 (NCES 2016-013). 2015. Available online: https://nces.ed.gov/pubs2016/2016013.pdf (accessed on 22 April 2020).

8. Jones, B.E.; Slate, J.R. Differences in academic and technical awards at Texas community colleges over time: A within groups comparison. Int. J. Univ. Teach. Fac. Dev. 2014, 4, 1-9.

9. Brown, R.S.; Conley, D.T. Comparing state high school assessments to standards for success in entry-level university courses. Educ. Assess. 2007, 12, 137-160. [CrossRef]

10. Combs, J.P.; Slate, J.R.; Moore, G.W.; Bustamante, R.M.; Onwuegbuzie, A.J.; Edmondson, S.L. Gender differences in college preparedness: A statewide study. Urban Rev. 2010, 42, 441-457. [CrossRef]

11. Palmer, R.T.; Davis, R.J.; Moore, J.L., III; Hilton, A.A. A nation at risk: Increasing college participation and persistence among African-American males to stimulate U.S. global competiveness. J. Afr. Am. Males Educ. 2010, 1, 105-125.

12. U.S. Department of Treasury. New Report from Treasury, Educational Department: The Economic Case for Higher Education. 2012. Available online: http://www.treasury.gov/press-center/press-releases/Pages/ tg1620.aspx (accessed on 23 April 2020).

13. Obama, B.H. Executive Order: White House Initiative on Educational Excellence for African Americans. 2012. Available online: http://www.Whitehouse.gov/the-press-office/2012/07/26/executive-order-Whitehouse-initiative-educational-excellence-african-am (accessed on 23 April 2020).

14. Gay, G. Culturally Responsive Teaching: Theory, Research, and Practice; Teachers College Press: New York, NY, USA, 2010.

15. Forbes, J.D. Teaching Native American values and cultures. In Teaching Ethnic Studies: Concepts and Strategies; Banks, J.A., Ed.; National Council for the Social Studies: Washington, DC, USA, 1973; pp. 200-225.

16. Carjuzaa, J.; Ruff, W.G. When western epistemology and an indigenous worldview meet: Culturally responsive assessment in practice. J. Scholarsh. Teach. Learn. 2010, 10, 68-79.

17. Ladson-Billings, G. But that's just good teaching! The case for culturally relevant teaching. Theory Pract. 1995, 34, 159-165. [CrossRef]

18. Frankenberg, E. (Ed.) Lessons in Integration: Realizing the Promise of Racial Diversity in American Schools; University of Virginia Press: Charlottesville, VA, USA, 2007.

19. McIntosh, P. White privilege: Unpacking the invisible knapsack. In Race, Class, and Gender: An Anthology Study; Andersen, M.L., Collins, P.H., Eds.; Wadsworth Publishers: New York, NY, USA, 1992; pp. 103-107.

20. Rhodes, C.M. Culturally responsive teaching with adult language learners. In Proceedings of the Adult Education Research Conference, Manhattan, KS, USA, 20-22 May 2015; Available online: http://newprairiepress.org/cgi/viewcontent.cgi?article=1142\&context=aerc (accessed on 24 April 2020).

21. Ladson-Billings, G. Toward a theory of culturally relevant pedagogy. Am. Educ. Res. J. 1995, 32, 465-491. [CrossRef]

22. Hutchison, L.F.; McAlister-Shields, L.; Jones, B. Culturally Responsive Instructional Strategies for Higher Education; Department of Curriculum and Instruction, University of Houston: Houston, TX, USA, Unpublished manuscript; 2018.

23. Delpit, L. Other People's Children: Cultural Conflict in the Classroom; New Press: New York, NY, USA, 1995. 
24. Ellis, E.M. The impact of race and gender on graduate school socialization, satisfaction with doctoral study, and commitment to degree completion. West. Stud. Black Stud. 2001, 25, 30-45.

25. Gardner, S.K. Fitting the mold of graduate school: A qualitative study of socialization in doctoral education. Innov. High. Educ. 2008, 33, 125-138. [CrossRef]

26. Banks, J. An Introduction to Multicultural Education; Allyn and Bacon: New Heights, MA, USA, 1994.

27. Nieto, S. Affirming Diversity: The Socio-Political Context of Multicultural Education; Allyn \& Bacon: Boston, MA, USA, 2003.

28. Garcia, R.L. Teaching for Diversity: A Guide to Greater Understanding; Solution Tree Press: Bloomington, IN, USA, 2011.

29. Hanley, M.S.; Noblit, G.W. Report on Cultural Responsiveness, Racial Identity and Academic Success: A Review of Literature. Retrieved from The Heinz Endowments. 2009. Available online: http://www.heinz. org/UserFiles/Library/Culture-Report_FINAL.pdf (accessed on 24 April 2020).

30. Harmon, D.A. Culturally responsive teaching through a historical lens: Will history repeat itself? Interdiscip. J. Teach. Learn. 2012, 2, 12-22.

31. Milner, R.H., IV. Culturally relevant teaching in a diverse urban classroom. Urban Rev. 2011, 43, 66-89. [CrossRef]

32. Ladson-Billings, G. The Dreamkeepers: Successful Teachers of African American Children; Jossey-Bass Publishers: San Francisco, CA, USA, 1994.

33. Robinson, S.P.; West, J.E. Preparing inclusive educators: A call to action. J. Teach. Educ. 2012, 63, $291-293$. [CrossRef]

34. Rueda, R.; Stillman, J. The 21st century teacher: A cultural perspective. J. Teach. Educ. 2012, 63, $245-253$. [CrossRef]

35. American Psychological Association. Publication Manual of the American Psychological Association; American Psychological Association: Washington, DC, USA, 2010.

36. Irvine, J.J. Black Students and School Failure: Policies, Practices, and Prescriptions; Greenwood Press: New York, NY, USA, 1990.

37. Cochran-Smith, M.; Dudley-Marling, C. Diversity in teacher education and special education: The issues that divide. J. Teach. Educ. 2012, 63, 237-244. [CrossRef]

38. Moran, J. Culturally Relevant ESL Teaching for California Community College Teacher Educators. Master's Thesis, University of San Francisco, San Francisco, CA, USA, 2014. Available online: https://repository.usfca. edu/capstone/68 (accessed on 24 April 2020).

39. Young, E. Challenges to conceptualizing and actualizing culturally relevant pedagogy: How viable is the theory in classroom practice? J. Teach. Educ. 2010, 61, 248-260. [CrossRef]

40. Larke, P.; Wiseman, J.D.; Bradley, C. The minority mentorship project: Changing attitudes of preservice teachers for diverse classrooms. Action Teach. Educ. 1990, 12, 5-11. [CrossRef]

41. Baumgartner, D.; Bay, M.; Lopez-Reyna, N.A.; Snowden, P.A.; Maiorano, M.J. Culturally responsive practice for teacher educators: Eight recommendations. Mult. Voices Ethn. Divers. Except. Learn. 2015, 15, 44-58.

42. Robins, K.N.; Lindsey, R.B.; Lindsey, D.B.; Terrell, R.D. Culturally Proficient Instruction: A Guide for People Who Teach; Corwin Press: Thousand Oaks, CA, USA, 2006.

43. Williams, H.W. The White Architects of Black Education: Ideology and Power in America, 1865-1954; Teachers College Press: New York, NY, USA, 2001.

44. Bustamante, R.M.; Nelson, J.A.; Onwuegbuzie, A.J. Assessing schoolwide cultural competence: Implications for school leadership preparation. Educ. Adm. Q. 2009, 45, 793-827. [CrossRef]

45. Smith, D.R.; Ayers, D.F. Culturally responsive teaching and online learning: Implications for the globalized community college. Community College J. Res. Pract. 2014, 30, 401-415. [CrossRef]

46. Howard, T.C. Why Race and Culture Matter in Schools: Closing the Achievement Gap in America's Classrooms; Teachers College Press: New York, NY, USA, 2010.

47. Allen, I.E.; Seaman, J. Online nation: Five Years of Growth in Online Learning; Sloan Consortium: Needham, MA, USA, 2007.

48. Allen, I.E.; Seaman, J.; Poulin, R.; Straut, T.T. Online Report Card: Tracking Online Education in the United States; Online Learning Consortium, Inc.: Newburyport, MA, USA, 2015.

49. Heitner, K.L.; Jennings, M. Culturally responsive teaching knowledge and practices of online faculty. Online Learn. 2016, 4, 54-78. [CrossRef] 
50. Woodley, X.M.; Parra, J. (Re)framing and (Re)designing instruction: Transformed teaching in traditional and online classrooms. Transform. Dialogues Teach. Learn. J. 2019, 12, 1-11.

51. PeQueen, C. Cultural Competence in Higher Education Faculty: A Case Study. Ph.D. Thesis, Keiser University, Fort Lauderdale, FL, USA, 2016.

52. Ryan, J. Improving teaching and learning practices for international students: Implications for curriculum, policy, and assessment. In Teaching International Students: Improving Learning for all; Ryan, J., Carroll, J., Eds.; Routledge: London, UK, 2005; pp. 92-100.

53. Taylor, P.C. Counter-storying and the grand narrative of science (teacher) education: Towards culturally responsive teaching. Cult. Stud. Sci. Educ. 2011, 6, 795-801. [CrossRef]

54. Hammond, Z.L. Culturally Responsive Teaching and the Brain: Promoting Authentic Engagement and Rigor among Culturally and Linguistically Diverse Students; Corwin: Thousand Oaks, CA, USA, 2015.

55. Rea, D.W. Interview with Pedro Noguera: How to help students and schools in poverty. Natl. Youth-Risk J. 2015, 1, 11-21. [CrossRef]

(C) 2020 by the authors. Licensee MDPI, Basel, Switzerland. This article is an open access article distributed under the terms and conditions of the Creative Commons Attribution (CC BY) license (http://creativecommons.org/licenses/by/4.0/). 